Article

\title{
Can We Rely on Self-Assessments of Sense of Coherence? The Effects of Socially Desirable Responding on the Orientation to Life Questionnaire (OLQ) Responses
}

\author{
Timo Lajunen ${ }^{1, *}$ and Esma Gaygisiz ${ }^{2}$ \\ 1 Department of Psychology, Norwegian University of Science and Technology, NO-7491 Trondheim, Norway \\ 2 Department of Economics, Middle East Technical University, 06800 Ankara, Turkey; esma@metu.edu.tr \\ * Correspondence: timo.lajunen@ntnu.no
}

Received: 26 August 2019; Accepted: 29 September 2019; Published: 1 October 2019

check for updates

\begin{abstract}
A large number of studies in health psychology have shown that sense of coherence (SOC) is an essential factor in wellbeing and health. SOC is most commonly measured with the Antonovsky's Orientation to Life Questionnaire (OLQ), which has been so far translated into at least 48 languages. Despite the vast popularity of the OLQ, the relationships between OLQ and socially desirable responding (impression management and self-deception) have not been studied. The purpose of the present study was to investigate the correlations between social desirability and Antonovsky's OLQ. Method: The first sample consisted of 423 students who completed the 13-item OLQ and the Eysenck Personality Questionnaire (EPQ), including the Lie scale. Also, the Balanced Inventory for Desirable Responding by Paulhus was administered together with the OLQ to 202 students. Results: SOC correlated positively with measures of social desirability among men but not among women. Hence, sex moderated the relationship between socially desirable responding and sense of coherence. Conclusions: Socially desirable responding and, especially, self-deception are positively related to high scores in SOC among men but not among women. The OLQ as a measure of sense of coherence can be used among women without worrying about the bias caused by socially desirable responding. When using the OLQ among men, the strong relationship between self-deception and sense of coherence should be taken into account.
\end{abstract}

Keywords: sense of coherence; self-deception; impression management; bias; social desirability; EPQ Lie

\section{Introduction}

Several studies have recently shown that sense of coherence (SOC) (Antonovsky 1987; Antonovsky and Sagy 1986) is an important salutogenic factor related to many aspects of psychological and somatic wellbeing. High SOC scores have been reported to correlate with other measures of generalized perception of self and environment, e.g., locus of control and hardiness (Albino et al. 2016; Flannery et al. 1994; Korotkov and Hannah 1994; Perenc and Radochonski 2016; Skirka 2000; Waite et al. 1999), with psychological adjustment, e.g., state and trait anxiety and depression (Frenz et al. 1993; Gåfvels et al. 2016; Järvholm et al. 2016; Kaiser et al. 1996; Mattisson et al. 2014; Pillay et al. 2015; Schnyder et al. 2000), with perceived work stress (Mackie et al. 2001; Runeson and Norbäck 2005), health, and wellbeing (Cowlishaw et al. 2013; Feldt 1997; Hassmen et al. 2000; Pallant and Lae 2002), with health behaviors (Speirs et al. 2016; Waite et al. 1999) and risk taking (Lajunen et al. 1998; Lajunen and Summala 1995). 
The Orientation to Life Questionnaire (OLQ) (Antonovsky 1987, 1993; Antonovsky and Sagy 1986) was designed to measure three components of SOC: comprehensibility (CO: sense that life events are explicable and predictable), manageability (MA: feeling that one has resources to meet demands in life), and meaningfulness (ME: life demands seen as a challenge rather than a burden). According to Antonovsky's theory (Antonovsky 1987, 1993) and empirical findings (Bernabé et al. 2009; Bonacchi et al. 2012; Feldt et al. 2007; Feldt and Rasku 1998; Gana and Garnier 2001; Moksnes and Haugan 2014) these three components are strongly interrelated and form a common SOC factor. So far, the OLQ has been used in at least 49 different languages and in at least 48 different countries (Eriksson and Mittelmark 2017).

Despite the great interest in SOC among health psychologists, no studies about the role of social desirability bias in the OLQ answers have yet been published. The self-reports of personality, attitudes, and behavior are, however, inaccurate or even biased to some extent, because at least some subjects tend to engage in socially desirable responding (Nederhof 1985; Paulhus 1984; Paulhus 1991; Paulhus and Reid 1991). In addition to deliberate impression management (faking), the self-reports may be biased by self-deception, which can be characterized as a positively biased but subjectively honest self-description (Paulhus 1984; Verkasalo and Lindeman 1994). According to Paulhus (1991), impression management should be controlled when it is conceptually independent of the trait being assessed but still contributes to the self-reported scores of that trait, whereas self-deception should be taken into account, but not necessarily controlled, if it is linked to content variable (Paulhus 1984; Paulhus 1991).

It can be hypothesized that the OLQ is somewhat vulnerable to bias caused by impression management or self-deception, as it relies on the subject's ability to assess his/her feelings and willingness to report them. Earlier studies have suggested that the OLQ answers may be contaminated by emotionality to some degree (Flannery and Flannery 1990; Flensborg-Madsen et al. 2005; Korotkov and Hannah 1994; Korotkov 1993). The effects of social desirability on responses may be even more severe with OLQ than with scales asking about behavior. It is presumably more difficult to get accurate measures of feelings and emotions than of behaviors. This study aims to investigate the role of different types of social desirability in OLQ answers by using two independent samples.

\section{Method}

\subsection{Participants}

The analyses described in the present paper are based on the analysis of two different student samples. The data were collected among psychology undergraduates during lectures. Since the questionnaires were distributed during the class hours, all participants of the lecture filled in a questionnaire. We can say, therefore, that the samples represent well the Finnish undergraduates studying psychology. The students did not receive any reward (money or course credits) for their participation in the study. The respondents did not fill in any identification information (except sex and age) and were assured about anonymity. The sample characteristics are summarized in Table 1. 
Table 1. Description of the samples and reliability coefficients for the Orientation to Life Questionnaire (OLQ).

\begin{tabular}{ccc}
\hline & Sample 1 & Sample 2 \\
\hline Sample characteristics & & \\
N & 423 & 202 \\
Population & students & students \\
Mean age (SD) & $23.8(16.7)$ & $24.3(6.06)$ \\
Gender distributions & $16.8 \%$ male & $31.2 \%$ male \\
Mlpha and McDonald's omega (in parenthesis) & & \\
reliability coefficients & & \\
Comprehensiveness (CO) & $0.74(0.75)$ & $0.82(0.83)$ \\
Manageability (MA) & $0.62(0.63)$ & $0.76(0.76)$ \\
Meaningfulness (ME) & $0.73(0.74)$ & $0.81(0.81)$ \\
Sense of Coherence (SOC) & $0.86(0.86)$ & $0.91(0.91)$ \\
Eysenck Personality Questionnaire (EPQ) Lie Scale & $0.97(0.97)$ & - \\
Self-deception (SD) & - & $0.85(0.87)$ \\
Impression Management (IM) & - & $0.81(0.82)$ \\
\hline
\end{tabular}

\subsection{Measures}

The Finnish translation by Kalimo, Vuori, and Kalimo (Kalimo and Vuori 1990) of the 13-item OLQ was used for both samples. The Finnish version of the Eysenck Personality Questionnaire (EPQ) (Eysenck and Eysenck 1975; Eysenck and Eysenck 1994; Haapasalo 1990) including the Lie scale was administered to sample 1, whereas sample 2 completed the Finnish version of the Balanced Inventory of Desirable Responding (BIDR) by Paulhus (1991). BIDR is composed of impression management (IM) and self-deception scales (SD). The forms were distributed to undergraduate students in classrooms. Participants were asked not to write their names on the questionnaires and were assured that the answers would be treated in strict confidence.

The Cronbach's alpha (Cronbach 1951) and McDonald's omega (McDonald 1999) reliabilities of the OLQ scales (CO, MA, ME, SOC), EPQ-L scale, and BIDR IM and SD scales are listed in Table 1.

\section{Results}

\subsection{Reliability of the OLQ Scales}

The Cronbach alpha and McDonald's omega coefficients were used for assessing the reliability of the scales. The widely referred rule of thumb about reliabilities states that reliabilities over 0.70 are considered "acceptable", reliability coefficients over 0.80 are "good", and reliability coefficients over 0.90 are "excellent" (Nunnally 1978). Table 1 shows good reliability (over 0.80) for the 13-item OLQ scale in both samples. The subscale reliabilities for the CO and ME scale were acceptable in both samples, whereas the reliability coefficients for the MA scale were below 0.70 in sample 1.

\subsection{Correlations between the EPQ Lie Scale and the OLQ}

The EPQ Lie scale was regarded initially merely as a scale to detect faking (Eysenck and Eysenck 1975) but has recently recognized as describing a personality factor denoting some degree of social naivety or conformity. In the present study, the EPQ was first administered together with the OLQ in sample 1.

Correlation coefficients between the EPQ Lie scale and the OLQ scales are presented in Table 2 for men and women, separately. In addition to $p$-values, bias-corrected bootstrap confidence intervals based on 1000 bootstrap samples were calculated to control the possible bias due to the small sample sizes. Table 2 shows that the correlations between the OLQ and the Lie scale were statistically significant, ranging from 0.31 to 0.42 for men but statistically non-significant and close to zero for women. Correlation coefficients corrected for dis-attenuation were also calculated to compute the 
correlation between EPQ L and OLQ scales without the weakening effect of the measurement error. These dis-attenuated correlations are based on the assumption that all measures are perfectly reliable (alpha coefficient of 1.0). The dis-attenuated Pearson correlation coefficients ranged from 0.40 to 0.50 for men but remained small (0.02-0.03) for women. The dis-attenuated correlations between the EPQ Lie and the OLQ scales indicate that EPQ L is moderately related to sense of coherence among men but not among women.

Table 2. Correlations, dis-attenuated correlations, and bias-corrected bootstrap confidence intervals $(95 \% \mathrm{BCI})$ between the OLQ scales and the questionnaires measuring social desirability among men and women.

\begin{tabular}{|c|c|c|c|c|c|c|c|c|}
\hline & \multicolumn{4}{|c|}{ Men } & \multicolumn{4}{|c|}{ Women } \\
\hline & $\mathrm{CO}$ & MA & ME & SOC & $\mathrm{CO}$ & MA & ME & SOC \\
\hline \multicolumn{9}{|l|}{ EPQ-Lie $^{1}$} \\
\hline Pearson $\mathrm{r}$ & $0.42^{* * *}$ & $0.31^{* *}$ & $0.34^{* *}$ & $0.41^{* * *}$ & 0.03 & 0.03 & -0.03 & 0.02 \\
\hline Dis-attenuated $\mathrm{r}$ & $0.50^{* * *}$ & $0.40^{* * *}$ & $0.40^{* * *}$ & $0.45^{* * *}$ & 0.04 & 0.04 & 0.04 & 0.02 \\
\hline 95\%BCI upper & 0.24 & 0.08 & 0.17 & 0.23 & -0.05 & -0.03 & -0.09 & -0.06 \\
\hline 95\%BCI lower & 0.57 & 0.49 & 0.49 & 0.57 & 0.27 & 0.27 & 0.18 & 0.27 \\
\hline \multicolumn{9}{|l|}{ Impression } \\
\hline \multicolumn{9}{|l|}{ Management ${ }^{2}$} \\
\hline Pearson $r$ & $0.58^{* * *}$ & $0.54^{* * *}$ & $0.52^{* * *}$ & $0.59 * * *$ & 0.1 & 0.09 & 0.08 & 0.1 \\
\hline Dis-attenuated $r$ & $0.71 * * *$ & $0.69 * * *$ & $0.64^{* * *}$ & $0.69 * * *$ & 0.12 & 0.11 & 0.1 & 0.12 \\
\hline 95\%BCI upper & 0.08 & 0.09 & 0.04 & 0.09 & -0.3 & -0.29 & -0.28 & -0.34 \\
\hline 95\%BCI lower & 0.79 & 0.75 & 0.74 & 0.8 & 0.36 & 0.36 & 0.34 & 0.38 \\
\hline \multicolumn{9}{|l|}{ Self-deception ${ }^{2}$} \\
\hline Pearson $\mathrm{r}$ & $0.63^{* * *}$ & $0.60 * * *$ & $0.59 * * *$ & $0.65 * * *$ & 0.06 & 0.04 & 0.11 & 0.07 \\
\hline Dis-attenuated $r$ & $0.75^{* * *}$ & $0.75^{* * *}$ & $0.71^{* * *}$ & $0.74^{* * *}$ & 0.07 & 0.05 & 0.13 & 0.08 \\
\hline 95\%BCI upper & 0.17 & 0.13 & 0.13 & 0.19 & -0.46 & -0.44 & -0.3 & -0.48 \\
\hline 95\%BCI lower & 0.8 & 0.78 & 0.78 & 0.82 & 0.35 & 0.34 & 0.38 & 0.39 \\
\hline
\end{tabular}

${ }^{1}$ Sample $1 ;{ }^{2}$ Sample $2 ;{ }^{* * *} p<0.001 ;{ }^{* *} p<0.01 ;{ }^{*} p<0.05$.

\subsection{Impression Management, Self-Deception, and the OLQ Scales}

The EPQ Lie score refers to a general tendency to embellish one's answers but does not distinguish between deliberate faking and self-deception. These two forms of social desirability, however, reflect different psychological processes and should, therefore, be treated differently. As suggested by Paulhus (1991), IM reflects contamination and should be controlled, whereas SD refers to genuine but positively biased self-description. In the present study, both forms of social desirability were measured together with the OLQ in sample 2.

Table 2 shows that IM correlated positively with the OLQ scales among men (range of correlations: 0.52-0.59) but not among women (range of correlations: 0.08-0.10). The dis-attenuated correlations (range: $0.64-0.71$ ) showed that the OLQ scores were strongly related to IM scores. The IM and OLQ correlations were small and statistically non-significant among women, even when the reliability of the instruments was taken into account.

The correlations between SD and OLQ scales among men were statistically significant and even stronger than between IM and OLQ scales (range: 0.59-0.65). Dis-attenuated correlations ranged from 0.71 to 0.75 , which indicates strong relationships between sense of coherence and SD. The correlations between OLQ scales and SD were statistically non-significant and weak among women.

\subsection{Sex as a Moderator in Social Desirability-The Sense of Coherence Relationship}

Table 2 shows that the relationship between social desirability (i.e., EPQ L, BIDR IM, BIDR SD) and OLQ scores was strongly sex-dependent: the relationship was strong among men in both samples and non-existent among women. In order to investigate the moderator effects of sex on social desirability-OLQ relationships, linear regression analyses with a moderator term were performed. 
In the first step, EPQ Lie scale scores were standardized, and a sex $x$ EPQ L moderator term was calculated. In the second step, four linear regression models with each OLQ scale score (CO, MA, $\mathrm{ME}, \mathrm{SOC}$ ) as a dependent variable were calculated. In these models, EPQ L score, sex, and moderator (sex $x$ EPQ L) served as independent variables. The results showed a moderator effect for EPQ L-CO relationship $(b=7.41$; beta $=0.20 ; \mathrm{t}=3.67, p<0.001)$ EPQ L-MA relationship $(\mathrm{b}=4.26$; beta $=0.15$; $\mathrm{t}=2.78, p<0.01)$; EPQ L-ME relationship $(\mathrm{b}=6.08$; beta $=0.20 ; \mathrm{t}=3.68, p<0.001)$, and EPQ L-SOC relationship $(\mathrm{b}=17.74$; beta $=0.22 ; \mathrm{t}=4.01, p<0.001)$. These moderator effects mean that EPQ L-OLQ relationships are different for men and women, as Table 2 indicates.

In the same way, the BIDR-OLQ relationships were further studied with moderator analysis. In the first step, BIDR IM and SD scale scores were standardized, and two moderator variables were included (sex $x$ BIDR IM and sex $x$ BIDR SD). In the second step, four linear regression models with each OLQ scale score (CO, MA, ME, SOC) as the dependent variable were calculated. In these models, BIDR IM, BIDR SD, sex, and moderators (sex x BIDR IM and BIDR SD) served as independent variables. The results showed a moderator effect for the BIDR SD-CO $(b=3.31$; beta $=0.37 ; \mathrm{t}=2.59, p<0.01)$ relationship but not for the BIDR IM-CO relationship $(\mathrm{b}=0.13$; beta $=0.01 ; \mathrm{t}=0.10, p=0.922)$. In the BIDR-MA relationship, the moderator effect of BIDR SD was statistically significant $(b=2.71$; beta $=0.39 ; \mathrm{t}=2.63, p<0.01)$, while no moderator effect of BIDR IM x sex was detected $(b=-0.02$; beta $=-0.00 ; \mathrm{t}=-0.02, p=0.981)$. A moderator effect for sex was also found in the BIDR SD-ME relationship $(b=2.10$; beta $=0.31 ; t=2.09, p<0.05)$, but not for BIDR IM $(b=0.45 ;$ beta $=0.07 ; t=0.45$, $p=0.657$ ). The relationship between BIDR scales and total OLQ (SOC) scores followed the same pattern as that observed with the three OLQ subscales. A moderator effect for the BIDR SD-SOC relationship was found $(\mathrm{b}=8.12$; beta $=0.40 ; \mathrm{t}=2.75, p<0.01)$, while no moderator effect on the BIDR IM-SOC relationship was detected $(b=0.55$; beta $=0.03 ; t=0.19, p=0.853)$. These results show that the BIDR SD-OLQ relationship is moderated by sex. This moderation was not found for BIDR IM scores, which might be explained by the high correlation between BIDR IM and BIDR SD ( $\mathrm{r}=0.81, p<0.001)$.

\section{Discussion}

Several studies have demonstrated SOC to be an important factor contributing to mental and physical wellbeing. Together with the growing evidence of the importance of SOC as a health resource, questions of psychometric properties, validity, and reliability of the OLQ-an instrument developed to measure SOC - have been raised. For example, research findings concerning OLQ factor structure have supported both one-factor and three-factor models (Bernabé et al. 2009; Bonacchi et al. 2012; Ding et al. 2012; Moksnes and Haugan 2014; Sandell et al. 1998).

Reliability analyses of OLQ scales (CO, MA, ME, SOC) in two Finnish samples showed a good level of reliability ( 0.86 and 0.91 ) for the 13 -item OLQ scale. The only reliability below the 0.70 threshold (0.62) was one of the MA scales in sample 1. Since the alpha reliability coefficient is directly related to the number of items, we can assume that the low reliability is partly explained by the small number of items (four items) in MA scale. While the other subscales (and also MA in sample 2) showed an acceptable level of reliability (over 0.70), the full 13-item OLQ showed better reliability than the subscales. One conclusion from this result is that the total score based on 13-items should be used instead of less reliable subscales. While this conclusion is certainly correct in terms of Antonovsky (1987) view of SOC as a holistic concept, earlier studies show that SOC based on CO, MA, and ME shows high construct validity and reliability (Lajunen 2018). Considering earlier studies and the results of the current study, we can conclude that the choice between one OLQ total score and three OLQ scale scores should be based on the aims of the study in which OLQ is used. If the aim is to measure CO, MA, and ME scores, it is advisable to use the 29-item OLQ instead of the short 13-item scale.

Despite the vast popularity of SOC and a vast interest in the psychometric properties of OLQ, the role of social desirability in SOC has remained unexamined. In the present study, the influence of social desirability on SOC scores was addressed by examining correlations between the OLQ and the EPQ Lie scale (Eysenck and Eysenck 1975) and BIDR (Paulhus 1991). The results showed that 
almost all OLQ scale scores were somewhat biased by social desirability among male respondents. The dis-attenuated correlations between EPQ Lie scale and OLQ scales ranged from 0.40 to 0.50, which shows that the OLQ scores are moderately influenced by EPQ Lie scores. Whether this can be considered as a "contamination" by lying depends on how EPQ Lie scores are interpreted.

According to Paulhus (1991), IM score refers to the deliberate tendency to give favorable self-descriptions to others and comes, therefore, close to lying and falsification. The present study showed that male participants scoring high in IM also scored high in OLQ ( $\mathrm{r}=0.52-0.59)$. When the correlation coefficients were corrected for the effect of the measurement error, they ranged from 0.64 to 0.71 , which indicates a severe effect of impression management on the sense of coherence scores (or vice versa). This result emphasizes the importance of paying attention to factors which might increase the probability of impression management and, thus, decrease the reliability of the OLQ. In the present study, the participants were assured that their responses would be treated in the strictest confidence. In addition, the participants answered the questionnaires anonymously. These procedures naturally minimize the bias caused by IM. This kind of total anonymity based on testing a large group simultaneously might not be easily achieved, say, in clinical settings where OLQ is administered to patients. Therefore, the possibility of distortion in OLQ scores should be kept in mind and corrected statistically if necessary.

In contrast to IM, self-deception as an unintentional over-positive view of oneself might help individuals to cope with the demands of everyday life. SD has been found to be intrinsically linked to positive personality constructs such as psychological adjustment (Paulhus and Reid 1991; Taylor and Brown 1988), high self-esteem (Paulhus and Reid 1991; Robins et al. 2001), and lack of neuroticism (Davies et al. 1998; Otter and Egan 2007). In the present study, similar relationships between SD and SOC were found. Among men, the correlations between OLQ scale scores and self-deception were even higher than the ones between impression management and sense of coherence. It is possible that a positive relationship between SOC and mental and physical wellbeing can partly be explained by a link between positive attitude to oneself and health. Hence, having a high SOC might even require a slightly positively biased attitude to oneself.

Correlations between the sense of coherence and all measures of socially desirable responding, including EPQ Lie scores and BIDR impression management and self-deception scores, were high among men but not among women. Moderator analyses showed that sex moderated all relationships between EPQ Lie scores and BIDR IM and SD scores: the effect of socially desirable responding was found for men but not for women. Interestingly, when the effects of impression management and self-deception scores on the sense of coherence were analyzed by using regression analysis with a moderator variable (sex $x$ BIDR scale), the moderator effects were found only for self-deception. This finding, together with high correlations, on the one hand, between self-deception and sense of coherence and, on the other hand, between self-deception and impression management indicate that the effect of social desirability on the sense of coherence is predominantly caused by self-deception, which also explains a large proportion of variance in impression management. Hence, the sense of coherence scores was not "contaminated" by lying or deliberate impression management but instead reflected an overly positive view of oneself which can be labeled as self-deception. This is understandable because the participants would not have benefitted from embellishing their answers.

It is interesting that the socially desirable responding (self-deception) was related to sense of coherence among men but not among women. This result might indicate that the origins of the sense of coherence-i.e., seeing one's life manageable, meaningful, and understandable-are different for Finnish men with respect to for Finnish women. Another possibility is that men and women have different response styles, which is reflected in both measures of social desirability and sense of coherence. For example, especially young men might be more likely than women to choose extreme values in measures of social desirably and sense of coherence. Men endorsing a more traditional masculine gender role (e.g., assertiveness, achievement, and success) might score higher in both socially desirable responding and sense of coherence in order not to reflect their weaknesses or uncertainty. 
Earlier research has consistently demonstrated that men score higher on egoistic response tendencies and that women score higher on moralistic response tendencies (Lalwani et al. 2006). Thus, men and women are susceptible to different types of socially desirable responding (Steenkamp et al. 2010), which can also be reflected in OLQ responses. The different types of gender-related socially desirable responding may also be reflected in the inconclusive findings of sex differences in SOC scores reported in various studies. While one-third of the studies about SOC in adolescence have not found any differences between sexes, about two-thirds of the studies have reported a higher level of SOC among boys (Rivera et al. 2013). Since the present study did not include any gender role measures and was conducted only within one culture/country, it is impossible to explain why the male sample differed from the female one. It can only be said that the OLQ as a measure of sense of coherence might work differently among men and women, at least in Finland.

Some limitations of the study should be taken into account. While the gender distribution of the sample reflects the gender distribution in the population (psychology students), a small number of men in the sample prevents more detailed analyses about gender differences in socially desirable responding, response styles, and OLQ responses. Large and a more heterogeneous samples would allow the investigation of socially desirable responding and sense of coherence in different age groups. Moreover, the present study was a cross-sectional study in which the sense of coherence scores was correlated with indicators of socially desirable responding. This kind of mono-cultural study based on an ecological design (correlations) can reveal interesting relationships but is vulnerable to methodological biases. First of all, this study was based on student samples collected in one country (Finland). Sense of coherence is a highly culturally dependent concept, as any measure of meaning in life. Finnish respondents might emphasize different aspect as meaningful, comprehensible, or manageable than, say, people from more collectivist cultures. In the future, cross-cultural studies of the sense of coherence and its correlates are needed. Secondly, this study was based on surveys, which might increase the method bias in responses. While a multitrait-multimethod matrix (MMM) approach would be a much stronger design for detecting the possible effects of social desirability on the sense of coherence, it is challenging to design studies in which the sense of coherence and social desirability could be measured with various methods rather than with surveys only. In future studies, different methods for studying the effects of socially desirable responding on the sense of coherence should be investigated.

Author Contributions: Conceptualization, T.L.; Data curation, T.L.; Formal analysis, T.L. and E.G.; Investigation, T.L. and E.G.; Methodology, T.L. and E.G.; Writing—original draft, T.L.; Writing-review \& editing, E.G.

Funding: This research received no external funding.

Conflicts of Interest: The authors declare no conflict of interest.

\section{Abbreviations}

$\begin{array}{ll}\text { SOC } & \text { Sense of Coherence } \\ \text { OLQ } & \text { Orientation to Life Questionnaire } \\ \text { CO } & \text { Comprehensibility } \\ \text { MA } & \text { Manageability } \\ \text { ME } & \text { Meaningfulness } \\ \text { EPQ } & \text { Eysenck Personality Questionnaire } \\ \text { BIDR } & \text { Balanced Inventory of Desirable Responding } \\ \text { IM } & \text { Impression Management } \\ \text { SD } & \text { Self-Deception scales }\end{array}$

\section{References}

Albino, Judith, Allison L. B. Shapiro, William G. Henderson, Tamanna Tiwari, Angela G. Brega, Jacob F. Thomas, Lucinda L. Bryant, Patricia A. Braun, and David O. Quissell. 2016. Validation of the sense of coherence scale in an American Indian population. Psychological Assessment 28: 386-93. [CrossRef] [PubMed] 
Antonovsky, Aaron. 1987. Unraveling the Mystery of Health: How People Manage Stress and Stay Well. San Francisco: Jossey-Bass.

Antonovsky, Aaron. 1993. The structure and properties of the sense of coherence scale. Social Science and Medicine 36: 725-33. [CrossRef]

Antonovsky, Helen, and Shifra Sagy. 1986. The development of a sense of coherence and its impact on responses to stress situations. The Journal of Social Psychology 126: 213-25. [PubMed]

Bernabé, Eduardo, Georgios Tsakos, Richard G. Watt, Anna Liisa Suominen-Taipale, Antti Uutela, Jussi Vahtera, and Mika Kivimäki. 2009. Structure of the sense of coherence scale in a nationally representative sample: The Finnish Health 2000 survey. Quality of Life Research 18: 629-36. [CrossRef] [PubMed]

Bonacchi, Andrea, Guido Miccinesi, Silvia Galli, Francesca Chiesi, Mariangela Martire, Monica Guazzini, Alessandro Toccafondi, Lorenzo Fazzi, Verena Balbo, Duccio Vanni, and et al. 2012. The dimensionality of Antonovsky's sense of coherence scales. An investigation with Italian samples. TPM-Testing, Psychometrics, Methodology in Applied Psychology 19: 115-34. [CrossRef]

Cowlishaw, Sean, Sylvia Niele, Karen Teshuva, Colette Browning, and Hal Kendig. 2013. Older adults' spirituality and life satisfaction: A longitudinal test of social support and sense of coherence as mediating mechanisms. Ageing and Society 33: 1243-62. [CrossRef]

Cronbach, Lee J. 1951. Coefficient alpha and the internal structure of tests. Psychometrika 16: 297-334. [CrossRef]

Davies, Martin F., Christopher C. French, and Edmund Keogh. 1998. Self-Deceptive Enhancement and Impression Management Correlates of EPQ-R Dimensions. Journal of Psychology: Interdisciplinary and Applied 132: 401-6. [CrossRef]

Ding, Yan, Leiping P. Bao, Hao Xu, Yanzhu Hu, and Ingalill R. Hallberg. 2012. Psychometric properties of the Chinese version of Sense of Coherence Scale in women with cervical cancer. Psycho-Oncology 21: 1205-14. [CrossRef]

Eriksson, Monica, and Maurice B. Mittelmark. 2017. The Sense of Coherence and Its Measurement. In The Handbook of Salutogenesis. Edited by M. B. Mittelmark, S. Sagy, M. Eriksson, G. F. Bauer, J. M. Pelikan, B. Lindström and G. A. Espnes. Cham: Springer.

Eysenck, Hans J., and Sybil B. G. Eysenck. 1975. Manual of the Eysenck Personality Questionnaire. London: Hodder and Stoughton.

Eysenck, Hans. J., and Sybil B. G. Eysenck. 1994. Eysenck Personality Questionnaire (EPQ-R Adult): Comprising the $E P Q-$ Revised (EPQ-R) \& EPQ-R Short Scale. San Diego: EdITS/Educational and Industrial Testing Service.

Feldt, Taru. 1997. The role of sense of coherence in well-being at work: Analysis of main and moderator effects. Work and Stress 11: 134-47. [CrossRef]

Feldt, Taru, and Anne Rasku. 1998. The structure of Antonovsky's Orientation to Life Questionnaire. Personality and Individual Differences 25: 505-16. [CrossRef]

Feldt, Taru, Hanna Lintula, Sakari Suominen, Markku Koskenvuo, Jussi Vahtera, and Mika Kivimäki. 2007. Structural validity and temporal stability of the 13-item sense of coherence scale: Prospective evidence from the population-based HeSSup study. Quality of Life Research 16: 483-93. [CrossRef] [PubMed]

Flannery, Raymond B., Jr., and Georgina J. Flannery. 1990. Sense of coherence, life stress, and psychological distress: A prospective methodological inquiry. Journal of Clinical Psychology 46: 415-20. [CrossRef]

Flannery, Raymond B., Jr., John C. Perry, Walter E. Penk, and Georgina J. Flannery. 1994. Validating Antonovsky's Sense of Coherence Scale. Journal of Clinical Psychology 50: 575-77. [CrossRef]

Flensborg-Madsen, Trine, Søren Ventegodt, and Joav Merrick. 2005. Why is Antonovsky's sense of coherence not correlated to physical health? Analysing Antonovsky's 29-item Sense of Coherence Scale (SOC-29). The Scientific World Journal [Electronic Resource] 5: 767-76. [CrossRef]

Frenz, Arthur W., Michael P. Carey, and Randall S. Jorgensen. 1993. Psychometric Evaluation of Antonovsky's Sense of Coherence Scale. Psychological Assessment 5: 145-53. [CrossRef]

Gåfvels, Catharina, Margareta Hägerström, Kristina Rane, Alexandre Wajngot, and Per E. Wändell. 2016. Depression and anxiety after 2 years of follow-up in patients diagnosed with diabetes or rheumatoid arthritis. Health Psychology Open 3. [CrossRef]

Gana, Kamel, and Stéphanie Garnier. 2001. Latent structure of the sense of coherence scale in a French sample. Personality and Individual Differences 31: 1079-90. [CrossRef]

Haapasalo, Jaana. 1990. Factor Structures and Scoring of the Eysenck Personality Questionnaire and Zuckerman's Sensation Seeking Scale in Finland. Jyväskylä: University of Jyväskylä, Department of Psychology. 
Hassmen, Peter, Nathalie Koivula, and Antti Uutela. 2000. Physical exercise and psychological well-being: A population study in Finland. Preventive Medicine 30: 17-25. [CrossRef]

Järvholm, Stina, Malin Broberg, and Ann Thurin-Kjellberg. 2016. Risk factors for depression and anxiety among men and women planning for pre-implantation genetic diagnosis. Journal of Reproductive and Infant Psychology 34: 282-92. [CrossRef]

Kaiser, Charles F., David N. Sattler, Daniel R. Bellack, and Jennifer Dersin. 1996. A Conservation of Resources approach to a natural disaster: Sense of coherence and psychological distress. Journal of Social Behavior and Personality 11: 459-76.

Kalimo, Raija, and Jukka Vuori. 1990. Work and sense of coherence-Resources for competence and life satisfaction. Behavioral Medicine 16: 76-89. [CrossRef] [PubMed]

Korotkov, David L. 1993. An assessment of the (short-form) sense of coherence personality measure: Issues of validity and well-being. Personality and Individual Differences 14: 575-83. [CrossRef]

Korotkov, David, and T. Edward Hannah. 1994. Extraversion and emotionality as proposed superordinate stress moderators: A prospective analysis. Personality and Individual Differences 16: 787-92. [CrossRef]

Lajunen, Timo. 2018. Cross-Cultural Evaluation of Antonovsky's Orientation to Life Questionnaire: Comparison between Australian, Finnish, and Turkish Young Adults. Psychological Reports. [CrossRef] [PubMed]

Lajunen, Timo, and Heikki Summala. 1995. Driving experience, personality, and skill and safety-motive dimensions in drivers' self-assessments. Personality and Individual Differences 19: 307-18. [CrossRef]

Lajunen, Timo, Angela Corry, Heikki Summala, and Lawrence Hartley. 1998. Cross-cultural differences in drivers' self-assessments of their perceptual-motor and safety skills: Australians and Finns. Personality and Individual Differences 24: 539-50. [CrossRef]

Lalwani, Ashok K., Sharon Shavitt, and Timothy Johnson. 2006. What is the relation between cultural orientation and socially desirable responding? Journal of Personality and Social Psychology 90: 165-78. [CrossRef] [PubMed]

Mackie, Kathleen S., Carol K. Holahan, and Nell H. Gottlieb. 2001. Employee involvement management practices, work stress, and depression in employees of a human services residential care facility. Human Relations 54: 1065-92. [CrossRef]

Mattisson, Cecilia, Matts Bogren, and Vibeke Horstmann. 2014. Relationship of SOC with sociodemographic variables, mental disorders and mortality. Scandinavian Journal of Public Health 42: 434-45. [CrossRef]

McDonald, Roderick P. 1999. Test Theory: A Unified Treatment. Mahwah: Lawrence Erlbaum.

Moksnes, Unni K., and Gørill Haugan. 2014. Validation of the Orientation to Life Questionnaire in Norwegian Adolescents, Construct Validity across Samples. Social Indicators Research 119: 1105-20. [CrossRef]

Nederhof, Anton J. 1985. Methods of coping with social desirability bias: A review. European Journal of Social Psychology 15: 263-80. [CrossRef]

Nunnally, Jum C. 1978. Psychometric Theory, 2nd ed. New York: McGraw-Hill.

Otter, Zoe, and Vincent Egan. 2007. The evolutionary role of self-deceptive enhancement as a protective factor against antisocial cognitions. Personality and Individual Differences 43: 2258-69. [CrossRef]

Pallant, Julie F., and Lidia Lae. 2002. Sense of coherence, well-being, coping and personality factors: Further evaluation of the sense of coherence scale. Personality and Individual Differences 33: 39-48. [CrossRef]

Paulhus, Delroy L. 1984. Two-component models of socially desirable responding. Journal of Personality and Social Psychology 46: 598-609. [CrossRef]

Paulhus, Delroy L. 1991. Measurement and control of response bias. In Measures of Personality and Social Psychological Attitudes. Edited by J. P. Robinson, P. R. Shaver and L. S. Wrightsman. San Diego: Academic Press, pp. 17-59.

Paulhus, Delroy L., and Douglas B. Reid. 1991. Enhancement and Denial in Socially Desirable Responding. Journal of Personality and Social Psychology 60: 307-17. [CrossRef]

Perenc, Lidia, and Mieczysław Radochonski. 2016. Psychological predictors of seeking help from mental health practitioners among a large sample of polish young adults. International Journal of Environmental Research and Public Health 13. [CrossRef]

Pillay, Brindha, Stuart J. Lee, Lynda Katona, Sue De Bono, Sue Burney, and Sharon Avery. 2015. A prospective study of the relationship between sense of coherence, depression, anxiety, and quality of life of haematopoietic stem cell transplant patients over time. Psycho-Oncology 24: 220-27. [CrossRef]

Rivera, Francisco, Irene García-Moya, Carmen Moreno, and Pilar Ramos. 2013. Developmental contexts and sense of coherence in adolescence: A systematic review. Journal of Health Psychology 18: 800-12. [CrossRef] 
Robins, Richard W., Jessica L. Tracy, Kali Trzesniewski, Jeff Potter, and Samuel D. Gosling. 2001. Personality correlates of self-esteem. Journal of Research in Personality 35: 463-82. [CrossRef]

Runeson, Roma, and Dan Norbäck. 2005. Associations among sick building syndrome, psychosocial factors, and personality traits. Perceptual and Motor Skills 100: 747-59. [CrossRef] [PubMed]

Sandell, Rolf, Juhan Blomberg, and Anna Lazar. 1998. The factor structure of Antonovsky's Sense of Coherence Scale in Swedish clinical and nonclinical samples. Personality and Individual Differences 24: 701-11. [CrossRef]

Schnyder, Ulrich, Stefan Büchi, Tom Sensky, and Richard Klaghofer. 2000. Antonovsky's Sense of Coherence: Trait or state? Psychotherapy and Psychosomatics 69: 296-302. [CrossRef] [PubMed]

Skirka, Nicholas. 2000. The relationship of hardiness, sense of coherence, sports participation, and gender to perceived stress and psychological symptoms among college students. Journal of Sports Medicine and Physical Fitness 40: 63-70. [PubMed]

Speirs, Katherine E., Jenna T. Hayes, Salma Musaad, Angela VanBrackle, and Madeleine Sigman-Grant. 2016. Is family sense of coherence a protective factor against the obesogenic environment? Appetite 99: 268-76. [CrossRef] [PubMed]

Steenkamp, Jan B. E. M., Martijn G. De Jong, and Hans Baumgartner. 2010. Socially desirable response tendencies in survey research. Journal of Marketing Research 47: 199-214. [CrossRef]

Taylor, Shelley E., and Jonathon D. Brown. 1988. Illusion and Well-Being: A Social Psychological Perspective on Mental Health. Psychological Bulletin 103: 193-210. [CrossRef] [PubMed]

Verkasalo, Markku, and Marjaana Lindeman. 1994. Personal ideals and socially desirable responding. European Journal of Personality 8: 385-93. [CrossRef]

Waite, Phillip J., Steven R. Hawks, and Julie A. Gast. 1999. The correlation between spiritual well-being and health behaviors. American Journal of Health Promotion 13: 159-62. [CrossRef]

(C) 2019 by the authors. Licensee MDPI, Basel, Switzerland. This article is an open access article distributed under the terms and conditions of the Creative Commons Attribution (CC BY) license (http://creativecommons.org/licenses/by/4.0/). 